\title{
FILOSOFÍA DE LA HISTORIA E HISTORIA DE LA FILOSOFÍA EN LA OBRA DE RAMÓN XIRAU ${ }^{1}$
}

\author{
Roberto Dalla Mora \\ Universidad Autónoma de Madrid
}

RESUMEN: La obra de Ramón Xirau, autor perteneciente a la segunda generación de exiliados españoles de 1939, ha marcado profundamente la historia del pensamiento en lengua española de la segunda mitad del siglo XX, sobre todo en el contexto iberoamericano y mexicano.

Particularmente influyentes han sido sus estudios de carácter histórico-filosófico, que han acompañado a más de dos generaciones de autores latinoamericanos en el estudio de la filosofía.

Este trabajo se propone poner de relieve los elementos más característicos del enfoque metodológico adoptado por Ramón Xirau en sus trabajos históricofilosóficos, haciendo hincapié sobre la relación que mantienen con su original concepción de la filosofía de la historia.

Palabras clave: Ramón Xirau, historia de la filosofía, filosofía de la historia, exilio español, pensamiento exiliado, historia del pensamiento español, filosofía iberoamericana, filósofos catalanes.

\section{FILOSOFIA DELLA STORIA E STORIA DELLA FILOSOFIA IN RAMÓN XIRAU}

ABSTRACT: L'opera di Ramón Xirau, autore appartenente alla seconda generazione d'esiliati spagnoli del 1939, ha influito profondamente nella storia del pensiero in lingua spagnola della seconda metà del XX secolo, soprattutto, nel contesto iberoamericano e messicano.

1. Resultados de la investigación llevada a cabo en el marco del "Programa propio de ayudas para Formación del Personal Investigador. FPI-UAM" de la Universidad Autónoma de Madrid, convocatoria 2012. 
Sono stati particolarmente influenti i suoi lavori di carattere storico-filosofico, che hanno accompagnato nello studio della filosofia oltre due generazioni di autori latinoamericani.

Con questo lavoro vogliamo porre in risalto gli elementi caratteristici della metodologia che Xirau applica nelle sue opere storico-filosofiche, sottolineando la sua relazione con un'originale concezione di una filosofia della storia.

Parole chiave: Ramón Xirau, storia della filosofia, filosofia della storia, esilio spagnolo, pensiero esiliato, storia del pensiero spagnolo, filosofia iberoamericana, filosofi catalani.

En las últimas tres décadas han aparecido muchas publicaciones -artículos, homenajes y trabajos monográficos- que nos permiten afirmar, sin lugar a dudas, que Ramón Xirau ha sido y es uno de los autores más influyentes en la historia del pensamiento en lengua española de la segunda mitad del siglo XX². En España, Xirau es conocido casi exclusivamente por su obra poética -enteramente escrita en catalán-, gracias a la cual se ha convertido en una fígura de referencia dentro de la literatura catalana contemporánea ${ }^{3}$. También se le conoce por ser hijo y discípulo de uno de los pensadores más brillantes de la Edad de Plata española, Joaquín Xirau, y por pertenecer a la llamada "segunda generación de exiliados españoles".

Sin embargo, el escaso reconocimiento que hasta ahora ha tenido Ramón Xirau en España es inversamente proporcional a la fortuna que ha conocido su obra en la América de habla hispana y, particularmente, en México, el país donde se exilió con su familia en 1939, teniendo a la sazón quince años de edad. En efecto, libros como El péndulo y la espiral ${ }^{4}$, Palabra y silencio ${ }^{5}$, Poesía y conocimiento ${ }^{6}$, Cinco filósofos y lo sagrado ${ }^{7}$ han marcado profundamente la historia de

2. Cfr. González, J. (ed.), Presencia de Ramón Xirau. México, UNAM, 1986; Espinasa, J.M. (ed.), Poesía, ensayo y crítica. En la vida de Ramón Xirau; Espinasa, J.-M., Ramón Xirau en los jardines del tiempo. México, Editorial Jus, 2006; Velasco, A. (ed.), Xirau: 80 años. En homenaje a Ramón Xirau. México, UNAM, 2009; Valdés, M. (ed.), Celebración. 85 años de Ramón Xirau. México, UNAM, 2010; Bernardéz, M., Ramón Xirau: Hacia el sentido de la presencia. México, Dirección General de Publicaciones del Consejo Nacional para la Cultura y las Artes, (2010); Dalla Mora, R., "Invitación al pensamiento y a la obra de Ramón Xirau", AA.VV., Másteres de la UAM. Año Académico 2010-2011. Madrid, UAM Ediciones, 2013.

3. Sobre la obra poética de Ramón Xirau, cfr. Espinasa, J.-M. (ed), Poesía, ensayo; Cabrera, I., "Ramón Xirau: la verdad en la poesía y la pertenencia filosófica de las imágenes", Valdés, M. (ed), Celebración, pp. 35-44; y Dalla Mora, R., "Aproximación a la obra poética de Ramón Xirau: entre filosofía y mística". Philobiblion. Revista de literaturas hispánicas no 1, 2015, pp. 165-176.

4. Xirau, R., El péndulo y la espiral. México, Universidad Veracruzana, 1959.

5. Xirau, R., Palabra y silencio. México, Siglo XXI, 1968.

6. Xirau, R., Poesía y conocimiento. Borges, Lezama Lima, Octavio Paz. México, Joaquín Mortiz, 1978.

7. Xirau, R., Cinco filósofos y lo sagrado. Y un ensayo sobre la presencia. México, El Colegio Nacional, 1999. 
la filosofía mexicana y han contribuido a dar a conocer a autores de la literatura latinoamericana hoy en día reconocidos internacionalmente, entre otros, Octavio Paz.

Es precisamente Paz quien, elogiando la labor de Xirau como crítico literario, poeta, filósofo, editor y maestro, destaca su talante integrador, su capacidad para poner en diálogo disciplinas y culturas diferentes. De manera afortunada, en algún momento lo definió "hombre puente":

En primer término: puente entre sus dos vocaciones más ciertas y profundas, la poesía y la filosofía [...] la obra de Ramón Xirau también comunica a dos idiomas: el catalán y el castellano. [...] Ramón Xirau es hombre-puente, entre otras cosas, por ser un liberal catalán de México. [...] Debo mencionar otras [orillas]: el pensamiento de Xirau es un puente entre diversas generaciones poéticas -modernismo y postmodernismo, vanguardia y poesía contemporánea- y entre obras y personalidades opuestas o distantes: Sor Juana Inés de la Cruz y Xavier Villaurrutia, Vicente Huidobro y José Gorostiza, los poetas concretos del Brasil y Marco Antonio Montes de Oca y José Emilio Pacheco, Carlos Pellicer y Federico García Lorca. $^{8}$

Dentro de este general reconocimiento por su obra y pensamiento, hay una faceta de Ramón Xirau que, con respecto a las otras, ha gozado de más prestigio: se trata de su labor como historiador de la filosofía. Su libro más conocido es seguramente Introducción a la historia de la filosofía ${ }^{9}$, un manual de carácter histórico-filosófico publicado por primera vez en 1964 y que en 1998 contaba con trece reediciones. Por sus declaradas intenciones formativas, el tono y el estilo antidogmáticos y la amplia galería de autores y corrientes analizados, Introducción a la historia de la filosofía se convirtió en una referencia para más de dos generaciones de autores mexicanos y latinoamericanos y, hoy en día, sigue siendo empleado en muchas universidades latinoamericanas como manual de iniciación en los estudios filosóficos.

No es casual que sea precisamente un libro de carácter histórico-filosófico la aportación de Ramón Xirau más apreciada tanto por la academia como por el gran público. En efecto, en toda su obra, poética y filosófica, Xirau manifiesta siempre una marcada sensibilidad histórica y podríamos afirmar, atendiendo a su bibliografía, que el elemento "historiable" de las actividades humanas, particularmente la filosofía, representa una preocupación constante en su labor docente e investigadora. Así lo testimonia también José María Espinasa cuando, referiéndose a la mencionada Introducción, escribe que:

8. Paz, O., "El hombre puente". Espinasa, J.-M. (ed.), Poesía, ensayo, pp. 294-310.

9. Xirau, R., Introducción a la historia de la filosofía. México, UNAM, 1964. 
Este concepto -la historia- es central en él, no sólo porque es el trasfondo sobre el cual escribe su libro, sino porque se reconoce en ella, explica y se explica en su sentido de continuidad ${ }^{10}$

Todo lo dicho hasta ahora parece sugerir que a raíz de libros tan importantes como Introducción a la historia de la filosofía se encuentra una reflexión filosófica original sobre el sentido de la historia, lo cual, de ser cierto, nos permitiría hablar de una filosofía de la historia dentro de la obra de Ramón Xirau. Sin embargo, todo esto suena paradójico cuando es el mismo Xirau quien, en El péndulo y la espiral, afirma lo siguiente:

Quiero aclarar en este punto que no creo que exista ninguna filosofía de la historia. ${ }^{11}$

Para resolver esta aparente contradicción entre lo que Xirau manifiesta literalmente -la negación de la existencia y de la posibilidad de una filosofía de la historia- y lo que pone en práctica -una teoría filosófica sobre el sentido del desarrollo histórico-, tenemos que considerar aquellos elementos que perfilan su particular concepción de la historia, que de alguna manera podríamos llamar su filosofía de la historia.

La obra donde estos elementos se manifiestan más claramente es El péndulo y la espiral, publicada en 1959. Este libro puede entenderse como un recorrido crítico a través de las filosofías de la historia más destacadas de los siglos XIX y XX. El autor empieza por establecer una primera y fundamental distinción entre las filosofías que llama pendulares y las espirales. Xirau retoma los términos de la tradición histórico-filosófica y los redefine de la siguiente manera:

[...] filosofías de la historia que tienden al movimiento pendular, palabra que simboliza desde ahora a las filosofías de la repetición y de la monotonía que liga a las causas y a los efectos [...] y filosofías espirales -término que desde ahora simboliza el progreso espiritual ${ }^{12}$

La oposición formal que Xirau introduce entre filosofías pendulares y filosofías espirales refleja las clásicas oposiciones entre mecanicismo y vitalismo, estático y dinámico, absoluto y relativo. Sin degenerar en un maniqueismo filosófico -por otra parte contrario a su misma visión filosófica-, Xirau rechaza todas aquellas propuestas que quieren esquematizar e inmovilizar el dinámico flujo del pensamiento. La intención explícita de Xirau en El péndulo y la espiral es mostrar las limitaciones de una filosofía de la historia entendida en el sentido tradicional y, en cambio, señalar la validez teórica y vital de las que define, en términos muy generales, teorías sobre el desarrollo del espíritu humano.

10. Espinasa, J.-M., Ramón Xirau, p. 17.

11. Xirau, R., El péndulo, p. 11.

12. Xirau, R., El péndulo, pp. 11-12. 
Dentro de las filosofías pendulares -representantes de la manera clásica de entender la filosofía de la historia-, Xirau identifica tres grandes categorías: el materialismo histórico - que analiza teniendo en cuenta sobre todo las tesis marxistas-; el positivismo -tal como se encuentra expuesto en la obra de Comte-; y, finalmente, la teoría de las estaciones de las civilizaciones, clásicamente formulada por Spengler en La decadencia de Occidente. Varias son las dificultades que el catalán encuentra en cada una de estas teorías: veámoslas en el detalle.

Por lo que respecta al marxismo, Xirau se centra en señalar su contradicción interna debida a la constante tensión entre realismo e idealismo. En su reacción ante la enorme construcción hegeliana y el deseo de ésta de absolutizar todo lo real, Marx no logra exponer una teoría que se salve de la misma tendencia que es blanco de su crítica:

Marx parece negar, desde un principio, la existencia de todos los absolutos. Para él la evolución dialéctica de la historia está gobernada por causas económicas determinadas y necesarias. [...] Pero para Marx estas causas son la única causa y al afirmar su absoluta preminencia Marx se encarga de establecer un nuevo absoluto, oscilando constantemente entre el realismo y el idealismo, entre la tierra y la no tierra de la utopía. ${ }^{13}$

Según Xirau la propuesta de Marx tiene un interés y un carácter pragmático indudables, que residen en la intuición de una circunstancia injusta y que urge reparar: por ello Marx sacrificaría la teoría por la práctica, siendo dispuesto a admitir la contradicción para justificar el fin último:

Marx, que tiene la intuición de una injusticia y se revuelve contra ella, quiere también explicarla. Para hacerlo escribe la teoría de la plusvalía y de la acumulación del capital. [...] Pero el hecho es que a Marx le interesa menos atenerse a los datos concretos de la historia que dar fundamento a la revolución que considera inminente y necesaria. Su noción de una constante lucha de clases puede ser falsa, pero se sostiene como base pragmática de la acción. ${ }^{14}$

Al desarrollar su teoría "Marx quiere establecer una ley que sea, para el mundo del hombre, lo que es para el universo físico la ley de Newton"15 y en este intento mueve hacia un nivel de abstracción que entra en contradicción con una finalidad absolutamente pragmática como es la revolución. De acuerdo con Cole, Xirau ve en la teoría económica marxista una "construcción metafísica"16, lo cual convierte la filosofía de la historia de Marx en una teoría sin ninguna relación con la realidad mundana: precisamente lo contrario de lo que se proponía

\footnotetext{
13. Xirau, R., El péndulo, p. 22.

14. Xirau, R., El péndulo, pp. 24-25.

15. Xirau, R., El péndulo, p. 26.

16. Xirau, R., El péndulo, p. 28.
} 
ser. El catalán resume las contradicciónes intrínsecas en la filosofía de la historia marxista en estos términos:

Al convertir su filosofía de la historia en la interpretación de una serie de causas mecánicas que tienen una explicación pseudocientífica, Marx desarrolla una estática de la historia que nos hace renunciar a la libertad, nos abandona al fatalismo y a la doctrina de un Estado cuyo fin está en el Estado mismo [...] La idea de una dictadura del proletariado como medio para alcanzar a un fin mejor era contradictoria en sí misma. La dictadura, de medio que antes era se ha convertido en fin. ${ }^{17}$

Entre los varios síntomas que manifiestan el nivel de abstracción en el cual se mueve la filosofía de la historia marxista, el más llamativo -según el particular punto de vista de Xirau- sería su incapacidad para explicar los procesos creativos y artísticos. A la base de la teoría de Marx se encuentra el concepto de estructura, constituido por las relaciones económicas. Con el cambio de estructura también la sobreestructura, donde están confinadas las demás actividades humanas -incluido el arte-, está destinada a cambiar. Pues bien: si asumimos que el arte no progresa, como nos demuestra el hecho de que las grandes obras de arte de la antigüedad no pierden su valor, ¿cómo explica esto el marxismo? Simplemente, escribe Xirau, no lo hace:

Los grandes artistas y los grandes poetas son de su tiempo y trascienden ese tiempo, van más allá de las murallas de una época, en cuanto tocan fibras cordiales de nuestra existencia y de nuestras emociones continúan presentes. El arte no progresa. Lo que puede hacer el arte es ingresar en una región más alta donde las contingencias históricas no pueden llegar. El marxismo es, así, incapaz de explicar el arte y la poesía. Es incapaz, por consiguiente, de explicar la mitad de nuestra vida. ${ }^{18}$

No queda duda alguna de las razones por las que Xirau relega la filosofía de la historia marxista entre las filosofías pendulares. Sin embargo, el catalán se empeña en defender la importacia pragmática y el valor ético y moral de esta teoría:

Ello no quiere decir que las ideas que impulsan a Marx sean esencialmente falsas ni mucho menos que desechables [...] Marx no vale tanto por su construcción pseudocientífica como por la protesta que la inspira. La ciencia que Marx pretende desarrollar, mecanicista, limitada al reino de los movimientos pendulares, sirvió sobre todo como arma de combate y permitió que los obreros y los revolucionarios actuaran confiados en que no sólo la protesta, sino desde ahora la ciencia y la razón, estaban de su lado. ${ }^{19}$

17. Xirau, R., El péndulo, pp. 34-35.

18. Xirau, R., El péndulo, p. 32.

19. Xirau, R., El péndulo, p. 28. 
Debido a su vertiente prágmatica, aunque rechazando su filosofía de la historia, Xirau justifica y salva al marxismo. ${ }^{20}$ No hará lo mismo con otras propuestas filosóficas, que desechará por completo: es el caso del positivismo comtiano. La filosofía de la historia de Comte, presentada en su Curso de filosofía, según Xirau "nos interesa hoy en día más por lo que simboliza que por lo que vale"21. Lo que el positivismo comtiano simboliza, escribe Xirau de acuerdo con una interpretación que ya expuso De Lubac, sería el intento común del humanismo antiteísta del siglo XIX de negar a Dios -y, muy particularmente, el Dios cristiano-, para apropiarse de la grandeza humana, cuyo lugar sería inapropiadamente ocupado por un absoluto. Esta tendencia antiteísta, reconocible en modo general dentro de las corrientes post-hegelianas que intentan sustituir el absoluto "Dios" con otro relativo -sea este la historia de Marx, el superhombre Nietzscheano o la religión de la Humanidad de Feuerbach-, marcó profundamente los antecedentes franceses de Comte. En concreto, no se podría explicar el positivismo comtiano sin remitir a su fuente principal, la obra de Saint Simon.

Fundadores de una especie de socialismo utópico, Saint Simon y sus discípulos estuvieron obsesionados, entre otras cosas, con la construcción de canales y de vías de comunicación que pudieran acercar a los hombres los unos a los otros. Saint Simon justificó sus proyectos, desde un punto de vista teórico, recurriendo a la idea de eliminar cualquier obstáculo que impidiera el fin último, esto es: la realización de una hermandad universal donde, de acuerdo con las tendencias antiteístas ya comentadas, a la negación del absoluto "Dios" correspondiera su sustitución por el "Hombre".

La "familia" saint-simoniana - de esta manera se referían a la secta de los discípulos de Saint Simon por aquel entonces-, llevó al máximo extremo las ideas de su fundador. Enfantin, discípulo de Saint Simon, rector y jefe de la "familia", hubo de tomarse en serio las palabras de D'Eichatal, un miembro de la secta que, tras una supuesta iluminación recibida durante una visita a Notre Dame, afirmó "Jesús vive en Enfantin". Al saint-simoniano no quedó otra opción que dejarse crecer la barba y organizar su propia iglesia donde él, por supuesto, ocupó el lugar de "padre".

Según Xirau, dos son las cosas que tenemos que tener presentes a la hora de acercarnos a Comte: por un lado, que la "familia" saint-simoniana tuvo una influencia decisiva en el desarrollo de su pensamiento: así se explicaría, por ejemplo, la siguiente afirmación del francés, en una carta que dirigió a M. de Teleuze el 23 de Arquímedes del 63 (es decir, en fecha "profana", el 22 de abril de 1751):

20. Sobre este punto habría que investigar cuánto y cómo ha influido la relación que Xirau mantuvo con Adolfo Sánchez Vázquez, destacado teórico del llamado marxismo europeo. Sánchez Vázquez, además de ser amigo íntimo de Xirau, compartió con él la pasión por la poesía.

21. Xirau, R., El péndulo, p. 39. 
Estoy persuadido de que, antes de 1860, predicaré el positivismo en Notre Dame como la única religión real y completa. ${ }^{22}$

Por otro lado, que Saint-Simon se encargó de descubrir -o inventar-, unas leyes del desarrollo histórico que justificaran su acción. El fanatismo religioso saintsimoniano, y luego comtiano, tendría su origen precisamente en estos supuestos teóricos que los franceses presentaron como su filosofía de la historia:

Saint Simon se preocupó por la historia y por la filosofía de la historia. Y como filósofo de la historia creyó, como Comte habrá de creer más tarde, que el hombre moderno, poseedor de la ciencia de los hechos, es capaz de destruir las supersticiones. Entre ellas la que más peligra le parece que es la religión en su forma teológica. Por ello preconiza una nueva religión, una religión sin Dios, una religión en la cual los hombres sean a la vez sacerdotes y dioses, veneradores y venerados. ${ }^{23}$

Comte sistematizó la idea de Saint Simon y, en su análisis histórico, descubrió que la Humanidad entera, sin diferencias geográficas ni culturales, está destinada a una misma y única historia: desarrollarse a través de tres etapas, que Comte denomina la era teológica, la era metafísica y el estadio positivo.

En la primera el hombre deifica los objetos entregados por su percepción; en la segunda, busca la esencia de los hechos concretos en grandes explicaciones abstractas e imaginarias; finalmente, en la última etapa, el hombre se da cuenta de que la única forma de operar es atenerse a los hechos de modo científico y objetivo. A la primera época corresponden las construcciones de las religiones primitivas y la magia, a la segunda los edificios especulativos de la filosofía y de las grandes religiones $y$, a la tercera, el desarrollo de las ciencias positivas y, particularmente, el estudio de los hechos sociales y de la dinámica histórica, ciencia que Comte denomina "Sociología".

Ahora bien, precisamente allá donde culmina la especulación de Comte podemos entrever el germen que sustenta toda la crítica realizada por Xirau a su filosofía de la historia. Según el catalán, los estados descritos por Comte no resisten al análisis histórico. En efecto, la humanidad no puede pensarse en términos generales y de manera indiferenciada, es decir, prescindiendo de las características -que no caracteres-, propios de cualquier cultura. Aún prescindiendo del criterio fundamental de diferenciación de culturas, la dinámica histórica propuesta por Comte resulta contradictoria en los términos mismos en que se formula.

En efecto, el positivismo comtiano supone una firme creencia en la posibilidad de que el hombre pueda alcanzar la felicidad absoluta en la Tierra. Si la teleología utópica situaba esta circunstancia en un futuro más o menos próximo

22. De Lubac, H. El drama del humanismo ateo. Madrid, Encuentro, 2011, p. 138.

23. Xirau, R., El péndulo, p. 41. 
-así Bacon, por ejemplo, imaginaba la Nueva Atlántida donde el hombre dominaba la Naturaleza con la técnica-, Comte cree que ese tiempo ya ha llegado:

Para Comte la sociedad perfecta ya no está en el futuro. Está en el presente. Está en la nueva y previsible Notre Dame de sus oraciones positivistas. $^{24}$

Comte reduce de esta manera el futuro al presente. Por otro lado, la filosofía del positivismo no respeta tampoco la autonomía del tiempo pasado. En efecto, el hombre del estadio positivo, que se acerca a los hechos y a los fenómenos naturales mediante los instrumentos de la ciencia, es el mismo hombre que, en el estadio primitivo, investigaba la naturaleza mediante la magia y la superstición. El fin último de la búsqueda es la esencia del fenómeno, de los hechos en sí mismos que, por una vía y por otra, siguen conservando su misterio esencial:

También para el hombre teológico cuentan básicamente los hechos. La única diferencia entre el primitivo y el positivo es que el primero se acerca a los hechos mediante los instrumentos que le proporciona la magia, mientras que el segundo pretende hacerlo con los instrumentos de la ciencia. ${ }^{25}$

Lejos de proponer una ley dinámica y acorde al desarrollo del espíritu humano, el positivismo comtiano resume en tres etapas lo que Bréhier definió una "estática social". La realidad sigue siendo la misma en la era primitiva, en la teológica y en el estadio positivo. La pretensión positivista de "renunciar a conocer las causas íntimas de los fenómenos" y de conformarse con encontrar "sus leyes efectivas, es decir, sus relaciones invariables" ${ }^{26}$, confunde al hombre comtiano, destinado a repetir, etapa tras etapa, su tiempo pasado:

[...] si es verdad que el hombre ha convertido la alquimia en química y la astrología en astronomía, no es menos verdad que muchos hombres positivos -entre ellos el propio Comte- viven en el reino de las fantasías fetichistas, ni es menos verdad, tampoco, que para Comte, siempre consistente en contradicción, el hombre es siempre lo mismo. Las estructuras sociales son siempre para él las mismas, hechas y derechas desde un principio. $^{27}$

Los postulados teóricos que sustentan la filosofía de la historia de Comte, incapaces de dar cuenta del desarrollo del espíritu humano, en el momento en que eliminan a "Dios" como absoluto, no resisten a sustituirlo por uno nuevo: por ello, la incesante búsqueda de objetividad y cientificidad, propia del positivismo

24. Xirau, R., El péndulo, p. 45.

25. Xirau, R., El péndulo, p. 46.

26. Xirau, R., El péndulo, p. 44.

27. Xirau, R., El péndulo, p. 46. 
comtiano y, antes de él, de la utopía saint-simoniana, confluye en una manifiesta cuanto contradictoria nueva Religión de la Humanidad:

[...] la ciencia de Comte, o mejor, su cientifismo, le conduce a la Religión de la Humanidad, con su Papa, su mujer adorada en la Sabiduría y sus santos consagrados por los ritos del laboratorio. [...] Ya estamos en plena fantasía. Comte, como Enfantin, se siente inspirado y predicador de la nueva verdad religiosa. [...] Comte, Enfantin sistemático, cree llegado el reino de su papado personal desde el cual puede predicar la llegada de un mundo feliz. ${ }^{28}$

Debido al espíritu conciliador e integrador que predomina toda la obra de Xirau, es difícil encontrar un lugar donde el autor manifieste abiertamente una total aversión hacia una teoría filosófica en particular. Sin embargo, en lo que respecta al caso de la filosofía comtiana, está claro que Xirau toma distancia de ella y que de su análisis teorético, que considera obligatorio por su valor históricofilosófico, deduce solamente conclusiones negativas, relegando la filosofía de la historia comtiana a las filosofías pendulares:

El progreso es tan sólo una apariencia y se reduce a una serie de derivaciones, de color más o menos intenso, acerca de un mismo tema idéntico y eternamente repetido. La filosofía de la historia de Comte queda supeditada a la ley de la repetición de los hechos sociales y es, muy a las claras, una filosofía pendular. [...] El péndulo del positivismo se convierte en una flecha de ida y vuelta. Por una parte conduce al concepto moderno del hombre científicamente deshumanizado. Por otra, y dentro de la teoría misma de Comte, ateniéndonos a lo que dice, sin ver sus consecuencias históricas, el péndulo queda suspendido como aquella flecha que vuela y que no vuela, paso a paso infinitamente frenada, en el poema de Valéry, eco moderno del viejo Zenón de Elea. ${ }^{29}$

La crítica de Ramón Xirau cierra finalmente este recorrido a través de las filosofías pendulares con la filosofía de la historia de Oswald Spengler. El carácter cíclico de la teoría spengleriana, ampliamente descrita en La decadencia del Occidente, diferencia radicalmente la teoría del alemán de la postura marxista y positivista. En efecto, tanto Marx como los positivistas franceses centraron sus filosofías de la historia -que representan el núcleo de sus propuestas filosóficasen el concepto de progreso y son, por consiguiente, filosofías con tendencia lineal orientadas teleológicamente hacia un fin determinado (el estadio positivo en Comte y la dictadura del proletariado en Marx).

28. Xirau, R., El péndulo, p. 47.

29. Xirau, R., El péndulo, pp. 46-48. 
En Spengler desaparece el concepto de progreso, que deja espacio a una concepción cíclica de la historia:

Si en el marxismo pueden encontrarse elementos de progreso espiritual unidos a un pseudocientifismo mecanicista, si en el positivismo estos progresos se reducen a la aceptación de un nuevo dogma estático, en la filosofía de Spengler la repetición, ahora una nueva forma del viejo mito del eterno retorno, sigue en sus ciclos perfectamente delineados las horas del reloj, del nacimiento hasta la muerte. ${ }^{30}$

El mismo Spengler explica la filiación y el origen romántico de sus ideas que, como recuerda Xirau, remontan a las reflexiones de Goethe, Ibsen, Strindberg, Shaw, Nietzsche, Schopenauer, Hebbel, Engels, Marx, Mill y Dühring. El planteamiento spengleriano, más allá de su carácter cíclico, se caracteriza por otros dos elementos: por un lado, la creencia en la posibilidad de que el hombre es un animal consciente de su naturaleza y capaz de describir el desarrollo de la Humanidad. Por otro lado, la idea de que no se puede hablar de una sola civilización, sino de civilizaciones en plural.

El primero es un presupuesto teórico compartido en términos generales por todas las filosofías de la historia, puesto que justifica el mismo intento de reconstruir y explicar el desarrollo histórico. Sin embargo Spengler, desde su original enfoque, instaura un paralelo entre los organismos vivientes y las civilizaciones, llegando a la conclusión de que estas tienen que corresponder al ciclo vital que puede no solamente ser descrito, sino también previsto:

[...] si "el animal es una planta y algo más", si el hombre es un animal consciente de su naturaleza, la sociedad es el hombre y algo más, es el organismo biológico que llamamos civilización. El hombre se conoce, sabe que nace, crece, madura y muere. La civilización Occidental ha llegado también a darse cuenta de que las civilizaciones siguen un idéntico proceso. [...] Por esto el hombre de Occidente puede escribir una "morfología de la historia", el hombre de Occidente que sabe que toda la historia es siempre la misma historia. ${ }^{31}$

La idea spengleriana de que el análisis histórico tiene que abrirse a espacios geográficos fuera de los límites de la Europa Occidental, contrasta con la falta de diferenciación cultural tan rotundamente presente en Comte. Sin embargo, Spengler entra rápidamente en contradicción cuando afirma -desde un marco eurocéntrico característico de su época- que solamente el hombre Occidental conoce su destino y puede intervenir en él para modificarlo:

30. Xirau, R., El péndulo, p. 51.

31. Xirau, R., El péndulo, p. 52. 
Toda civilización lleva en sí el germen de su propia muerte si exceptuamos tal vez [...] la civilización alemana, gracias a la cual, gracias a cuya morfología de la historia llegará a establecerse el estado universal que habrá de salvar al Occidente de la misma ley mortal que Spengler pretendía establecer. ${ }^{32}$

Desde estos términos contradictorios -que reflejan la trayectoria socio-cultural que, a través el condicionamiento de oportunos catalizadores históricos, terminará confluyendo en el nacionalsocialismo-, Spengler describe las historias de las civilizaciones haciéndolas partícipes, como se ha dicho, del ciclo de la naturaleza y del ritmo de las estaciones. En La decadencia del Occidente las manifestaciones culturales -las creencias mágicas y religiosas, los descubrimientos científicos, los movimientos sociales, etc.- son consideradas como indicadores de la "estación" en la que se encuentra una civilización: a la primavera correspondería un despertar de la humanidad y un afán por conocer y poseer el mundo, que se refleja, por ejemplo, en los himnos védicos de la India o en los poemas homéricos griegos. El verano se caracterizaría por la maduración de la conciencia humana y la proliferación de ideas reformadoras (los Brahmanes en la India, los órficos en Grecia, Nicolás de Cusa y Lutero en Europa). El otoño es la estación del lluminismo, de la conciencia dirigida hacia sí misma (Buda, Sócrates, Voltaire, Rousseau, Locke...) y, finalmente, a la llegada del Invierno correspondería la decadencia de la civilización, con la fragmentación de todos los grandes sistemas de pensamientos otoñales (los Vedanta, el platonismo, el idealismo alemán...).

Mas, según Xirau, los esfuerzos realizados por Spengler en La decadencia de Occidente para llevar a cabo un edificio especulativo coherente y sistemático, como ya pasaba en el caso de la teoría comtiana, no resisten al análisis histórico. No cabe duda de que Spengler ha escrito un "bello poema"33, un himno a la igualdad de las civilizaciones y las culturas; sin embargo, las numerosas incoherencias históricas y el intento de reducir culturas lejanas en el tiempo y en el espacio a las categorías del pensamiento occidental moderno, acaban con cualquier pretensión realista de la filosofía de la historia intrínseca a esta teoría:

El cuadro lleno de climatología, temperaturas, auroras y atardeceres, culto de la sangre y florecimientos vitales que Spengler desborda a líneas llenas no puede dejar de llenarnos de perplejidades. ¿A quién se le ocurre suponer que los poemas homéricos son un principio, cuando son, en realidad, la síntesis de una gran civilización? ¿Qué tiene que ver Plotino con el Talmud? ¿En qué sentido la matemática invernal puede considerarse superior a la matemática de la primavera? ¿Cómo comparar el budismo y el "socialismo de 1900"? ?4

32. Xirau, R., El péndulo, p. 57.

33. Cfr. Xirau, R., El péndulo, p. 57.

34. Xirau, R., El péndulo, p. 56. 
Al igual que en el marxismo y en el positivismo comtiano, la teoría de las estaciones de Spengler prefiere un ideal de simetría antes que el íntimo curso del desarrollo histórico. En la medida en que han buscado sistematizar una realidad en constante cambio -irreductible, por un lado, a un único progreso lineal y, por otro, a la idea de un eterno retorno- Xirau ha definido las posturas de Marx, Comte y Spengler como filosofías pendulares, esto es, como filosofías de la repetición, "estados de espíritu que coinciden en cuanto niegan: el cristianismo, la existencia de Dios, la verdad de los principios espirituales" ${ }^{\prime \prime 3}$. En cuanto el limitado panorama que describen no coincide con el infinito y esencial horizonte de posibilidad que la vida ofrece al desarrollo de la humanidad, las filosofías pendulares resultan inútiles.

Como ya hemos dicho en un principio, contrarias a las filosofías pendulares estarían las filosofías espirales. Concretamente, en su obra Xirau expone y defiende solamente una teoría de este tipo: la filosofía de Bergson y, particularmente, la postura presentada por el francés en Las dos fuentes de la moral y de la religión. Cabe preguntarse si, al ser la única filosofía espiral que Xirau expone, no sea también, según su manera de ver, la única que cabe destacar en estos términos. Lo que está claro, es que el Bergson descrito en El péndulo y la espiral es un espíritu rebelde ante las interpretaciones mecanicistas de la historia. Es bastante probable que Xirau esté de acuerdo con la teoría de Bergson, puesto que dedica más de 27 páginas de su obra al comentario de Las dos fuentes de la moral (salta aquí a la vista la diferencia de actitud con respecto al positivismo comtiano, a cuya exposición, reconstrucción histórica y crítica corresponden apenas 10 páginas). Lo que está fuera de duda es su adhesión a la actitud del francés, empeñado en perseguir la dinámica de la vida humana, en lugar de atraparla y encorsetarla en un esquema mecánico y preestablecido. También Bergson ha elaborado unas "leyes históricas"-la ley de la dicotomía y del doble frenesí-, mas se trata de recursos utilizados "como él dice, por comodidad"36 y no tienen que ser interpretados como intentos de describir la realidad según un esquema de causa-efecto.

Por un lado, la propuesta de Bergson subraya un hecho objetivamente presente en la sociedad humana, a saber: la presencia constante de una dialéctica entre opuestos ideológicos donde, al agotamiento de una tendencia, se desarroIla otra opuesta:

En los individuos y en los grupos sociales las tendencias suceden por sucesión, no por simultaneidad. Y así, la ley que parece guiar los actos humanos es la que Bergson denomina ley del haz o ley de la dicotomía. [...] Cuando una tendencia empieza a desarrollarse intenta hacerlo hasta el agotamiento. Una vez anulada, la tendencia primera dejará su lugar a

35. Xirau, R., El péndulo, p. 58.

36. Xirau, R., El péndulo, p. 85. 
una segunda tendencia, generalmente de signo contrario a la primera que a su vez se desenvolverá hasta el agotamiento. ${ }^{37}$

El otro punto sobre el que Bergson insiste es la alternancia, en correspondencia con la dialéctica trazada ya por la ley de la dicotomía, de momentos históricos de entusiasmos ideológicos con momentos de equilibrio y estabilidad:

La ley de la dicotomía, o de la división de las tendencias, debe completarse con la ley del doble frenesí. [...] A un frenesí de ideal viene a substituirse, si por la palabra frenesí entendemos lo que entiende Bergson (un llevar hasta sus últimas consecuencias nuestros actos), un frenesí de quietud, de reposo y de equilibrio. ${ }^{38}$

A lo largo de toda su obra, Bergson ha intentado escapar del rigor simétrico y de las descripciones mecanicistas de la vida. Es el filósofo que ha antepuesto la libertad a la construcción de un edificio racional, con la consecuencia de que, por lo que respecta al tema que nos ocupa, "no hay que buscar en sus obras el sistema de filosofía de la historia con todo lo que estas palabras implican de rigor simétrico y de causalidades postuladas". ${ }^{39}$

Según Xirau, la filosofía de la historia de Bergson -o, en términos xiraunianos, su teoría del desarrollo del espíritu humano- es la que más se acerca a la realidad de la dinámica histórica:

Si la filosofía es una pura construcción de signos verbales idénticos entre sí, discontinuos, formales, Bergson no ha escrito una filosofía. Si la filosofía de la historia es simplemente la construcción detallada de un edificio que quiere comprender todos los hechos históricos bajo el signo de una misma ley rígida, inflexible, estática, fabuladora y cerrada, Bergson tampoco ha escrito una filosofía de la historia.

Pero si la historia y la filosofía de la historia son cosas de vida y no regla abstracta y aséptica, si son una dirección y un proyecto del ánimo libre que, siguiendo los impulsos de la creación y del amor, Ilega a llenarnos de esperanza y de gozo, Bergson ha escrito la única filosofía de nuestro tiempo. ${ }^{40}$

Nos parece que este largo y lapidario párrafo reúne sintéticamente todo lo expuesto hasta ahora. Según Ramón Xirau no existe una filosofía de la historia, y tampoco puede existir, en la medida en que busca construir una teoría mecánica del desarrollo histórico. Sin embargo, sí que existe la posibilidad de acercarse a la comprensión del curso histórico, persiguiendo su íntimo movimiento mediante

37. Xirau, R., El péndulo, p. 86.

38. Xirau, R., El péndulo, p. 86.

39. Xirau, R., El péndulo, p. 84.

40. Xirau, R., El péndulo, p. 89. 
el estudio de las expresiones vitales que lo constituyen. Por ello, el método histórico debe abrirse a las influencias artísticas, buscar los síntomas del cambio y de las variaciones históricas no solamente en los grandes acontecimientos sino también en las obras de filósofos, poetas, artistas y novelistas, testimonios de sus propios tiempos y circunstancias.

A modo de ejemplo, la última parte de El péndulo y la espiral está dedicada precisamente a emplear este nuevo método, que admite el recurso a géneros literarios normalmente ajenos a la consideración de los cánones histórico-filosóficos. Centrándose en la época contemporánea, Xirau detecta tres elementos que contribuirían a caracterizarla, a saber: la exasperada y exclusiva proyección hacia el futuro; la absolutización del presente y del instante; y el tradicionalismo. Está claro que los tres elementos mencionados se contradicen entre ellos, aunque el intento de Xirau es de caracterizar la época contemporánea precisamente señalando su copresencia, como resulta del análisis de los autores fundamentales del período estudiado.

Por lo que concierne el primer punto, nadie puede negar objetivamente que "el siglo XIX se caracterizaba por un especial entusiasmo hacia el progreso" ${ }^{\prime 41}$, tal como se pone de manifiesto, por ejemplo, en el ámbito artístico. En el arte contemporáneo de los primeros treinta años de 1900 dominó el vanguardismo, "termino militar y militante" que, si desde el punto de vista estético tuvo una importancia indudable e irrenunciable, en el ámbito moral condujo a consecuencias nefastas:

[...] el vanguardismo [...] indica que quienes lo profesan están más adelante que los otros, en las avanzadas futuras del siglo, en otro momento invivible del tiempo, en un mañana que ellos mismos contradicen al convertirlo, en sus vidas, en un hoy que pronto pasa a ser. ${ }^{42}$

Piénsese, como ejemplo de lo que acaba de mencionar Xirau, en el futurismo y en sus consecuencias políticas y en la adhesión de sus miembros a los movimientos fascistas. La importancia del tiempo futuro en la constitución metafísica del ser humano se encuentra argumentada y justificada también en autores clásicos del pensamiento filosófico occidental; sobre este punto, no podemos pasar por alto la referencia a Martin Heidegger y las reflexiones expuestas en su Ser y tiempo, donde encontramos el exacto reflejo de la actitud vanguardistas que acabamos de describir:

La primacía del advenir sobre el ser -es decir, el presente- y el sido -es decir, mi personal pasado intransferible- es la clave de la filosofía de Heidegger, quien precisa su dramática meditación cuando afirma que el hombre es un ser para la muerte y que el hombre está destinado a este

41. Xirau, R., El péndulo, p. 104.

42. Xirau, R., El péndulo, p. 105. 
irremediable fin precisamente porque es un ser histórico o, acaso más significativamente, el ser por el cual la historia viene al mundo. ${ }^{43}$

Desde luego, si la proyección del ser en el futuro se dramatiza en la justificación de la muerte como fin último del ser humano, no debe asombrar la proliferación de toda una literatura distópica que Xirau tiene bien presente en estas páginas: "A esta misma tendencia apocalíptica obedecen todas estas obras que podemos llamar utopías negativas, de Gas a 1984, de La guerra de los mundos y Cosas que vendrás, a R.U.R. y La Colonia penitenciaria"44. Así las cosas, -se pregunta Xirau- ¿cómo tenemos que actuar si solamente el futuro tiene sentido y el fin de este es la muerte, es decir, la anulación de nuestro ser? Según el catalánmexicano, se pueden identificar claramente tres actitudes de reacción a este pensamiento, una que se propone la superación a través de la violencia hacia este mismo ser contradictorio que nos constituye, en la búsqueda de un ser originario y arquetipo que no posee ninguna característica negativa; otra que intenta potenciar el ser humano y sus esenciales falacias con la potencia de la técnica; y otra, finalmente, que se entrega resignada a su destino sinsentido: en todos casos, nos encontramos ante actitudes funestas y deletéreas:

Podría decirse que el futuro debe fundarse en mitos irracionales como la velocidad, los gritos de Hitler o la sangre de que hablaba Spengler. Podrá creerse en el ideal también irracional, aunque tantas veces racionalizado, de una nueva Atlántica técnica que ya es previsible. Podrá aceptarse que el futuro significa, para el individuo, muerte, y entregarse, como lo hace Heidegger, a una suerte de filosofía de las resignación que si bien es pesimista carece del carácter moralizante del pesimismo de Séneca [...]: Calamitosus est animus futuri anxius. ${ }^{45}$

Paralelamente a este pensamiento que eleva el futuro a representante absoluto de la condición existencial humana, se desarrolla otra actitud centrada en la exaltación del instante y del tiempo presente. El filósofo y novelista Sartre es el autor elegido por Xirau para representar este tipo de pensamiento. Tras un rápido recorrido a través de las reflexiones contenidas en El ser y la nada, Xirau destaca la primacía del tiempo que de ellas se desprende con estas palabras:

El pasado [...] es un ser en sí, un ser imposible puesto que siempre se me presenta bajo la forma verbal del fui. Y esto significa que el pasado es aquello que no tengo posibilidad de concebir como no habiendo sido. Si contemplo mi pasado me percibo y me siento causado, determinado y necesario. El futuro es en cambio posibilidad indeterminada porque el futuro podemos decir que no es y de mi ser en el futuro que no lo soy. [...]

43. Xirau, R., El péndulo, p. 108.

44. Xirau, R., El péndulo, p. 108.

45. Xirau, R., El péndulo, p. 109. 
De esta afirmación de un pasado helado y convertido en la forma de la propia estatua y de esta afirmación de un futuro que me lanza de posibilidad en posibilidad, Sartre deduce la primacía del presente. ${ }^{46}$

Por un lado, las reflexiones sartreanas tienen notas positivas, pues implican un compromiso práctico y efectivo con el tiempo presente y, por ende, responsabilizan al ser humano en todo momento de sus actos. Por otra parte, está claro que las pretensiones del francés son en sí mismas irrealizables, puesto que requieren que el hombre esté constantemente consciente y arbitro de sus decisiones y, escribe Xirau, "es radicalmente imposible que el hombre pueda ser quien decida de su destino, quien lo haga, lo cree y lo viva" ${ }^{\prime \prime 7}$. A pesar de las contradicciones que Xirau señala dentro del pensamiento sartreano, cree que los peores resultados de las absolutización del presente se deducen del análisis de la "forma social de las grandes comunidades civilizadas" ${ }^{\prime 48}$. El autor propone como ejemplo el "hombre-organización" descrito por el filósofo y sociólogo William H. White:

El hombre-organización es precisamente el que aguanta y el que se aguanta. Ha dejado de ser persona para hipotecarse como individuo. Vive al día. Agota el presente. Es, en pocas palabras, el hombre convertido en cosa, institucionalizado en los bancos, las compañías, los laboratorios y las universidades. ${ }^{49}$

El hombre-organización puede asimilarse a la "masa" de Ortega y a la "nueva clase" de Djilas. Es el reflejo de un ser deshumanizado e infeliz, que vive en una sociedad en la cual su única norma es respetar los órdenes que se le imparten, sin cuestionamientos y rechazos:

Una sociedad manejada por la organización pura que eterniza un presente tan estulto como feliz, sería una sociedad de insectos, una sociedad sin historia y sin espíritu en la cual el 'debes porque debes' nos dominaría a todos en un trance de sonambulismo creado a base de hipnotismo eléctricos. ${ }^{50}$

Y si parece ciencia-ficción la imagen de una sociedad donde todos están controlados y obligados a moverse según un plan pre-establecido por una voluntad trans-individual, Xirau recuerda que, no hace mucho tiempo, Estados Unidos se había opuesto a acciones de bio-control por medio del cual, según afirmaba en 1956 Curtiss R. Shaffer al Congreso Nacional de Electrónica, es posible llegar un día a controlar la voluntad humana ${ }^{51}$. Señalamos, en este punto, cómo, a pocos

46. Xirau, R., El péndulo, pp. 112-113.

47. Xirau, R., El péndulo, p. 114.

48. Xirau, R., El péndulo, p. 115.

49. Xirau, R., El péndulo, p. 117.

50. Xirau, R., El péndulo, p. 121.

51. Cfr., Xirau, R., El péndulo, p. 121. 
años de distancia de las reflexiones de Xirau, el debate sobre la posibilidad de implantar un chip a los ciudadanos para monitorear constantemente su estado de salud se vuelve cada día más intenso. ¿Se trata del primer paso hacia el bio-control y la sociedad de insectos descrita por Xirau? Más allá de estas reflexiones, tendrá que haber quedado claro cómo, a pesar de sus posibles consecuencias positivas, la absolutización del tiempo presente y del instante lleva inexorablemente hacia modelos de sociedad totalmente deshumanizados.

Como última actitud característica de la época contemporánea, tras el afán por el futuro y la absolutización del presente, queda por analizar el tradicionalismo, es decir, la continua mirada hacia el tiempo pasado. Xirau no dedica realmente mucho espacio a esta cuestión, en tanto en cuanto la considera una postura simplista y contradictoria en los mismos términos en los que se propone:

Pocas frases aclaran el sentido contradictorio del tradicionalismo actual como aquello que cita Sartre copiando un título de un periódico de Vichy: "Mantener, tal es la divisa de la revolución nacional"52

Resumiendo: podemos decir que Xirau ve en la disolución de la idea del tiempo la característica fundamental de nuestra época contemporánea. Tanto si el hombre mira exclusivamente al futuro, como si el presente o el pasado son absolutizados, el resultado es el mismo: al hombre contemporáneo le falta una orientación temporal, lo cual lo condena a vivir en un paisaje de desolación que el catalán define con el término "crisis". Nos encontramos aquí con una palabra que, como veremos más adelante, Xirau elevará a categoría conceptual, fundando en ella su sistema histórico-filosófico y sus reflexiones sobre la filosofía de la historia.

Siguiendo en su análisis del tiempo contemporáneo, el autor detecta entonces dos actitudes características de las reacciones ante el fenómeno histórico de la crisis: el fariseísmo y la protesta:

Frente a ella [la crisis] han aparecido, llevadas al extremo, dos actitudes dominantes que si bien hemos heredado de los siglos anteriores no dejan de presentarse ahora como formas preponderantes de la actividad vital de buen número de nuestros contemporáneos. La primera de estas actitudes es el fariseísmo; la segunda es la protesta. ${ }^{53}$

Se considera fariseo "quien venera su propia falsedad y quien se somete a los dobleces y vericuetos secretos de su espíritu"54; en otras palabras, Xirau define como fariseo a aquel hombre que vive sin coherencia consigo mismo, consciente de que los ideales que defiende son falsos y, a menudo, inmorales. La protesta

52. Xirau, R., El péndulo, p. 125.

53. Xirau, R., El péndulo, p. 126.

54. Xirau, R., El péndulo, p. 126. 
se configura, entonces, como la reacción radicalmente opuesta al fariseísmo y es aquí, en la opinión de Xirau, donde mejor se identifica la reacción de la humanidad frente la crisis contemporánea. Sin embargo, también la protesta puede convertirse en un acto dañino para la sociedad humana, en el momento en que se absolutice y se justifique a priori su práctica:

Toda protesta es un camino; ninguna protesta puede constituirse en un fin. Y no sólo porque protesta y finalidad son términos contradictorios, sino porque la protesta solamente adquiere validez si al protestar para destruir quien protesta sabe afirmar para construir. [...] La protesta es fecunda cuando quien protesta es un alma sincera. Pero la protesta es un camino. Los que no saben verlo así acabarán por hacer de ella un nuevo absoluto en el corazón de la relatividad. Y ya hemos visto lo que sucede cuando los términos relativos se hacen absolutos. Los términos pierden su sentido y el hombre pierde conciencia de sus límites que es también perder conciencia de sus mejores posibilidades. ${ }^{55}$

Con estas reflexiones sobre la época contemporánea y su carácter crítico, Ramón Xirau concluye el recorrido que ha ido trazando en El péndulo y la espiral. Seguirá siendo este, durante mucho tiempo, uno de sus libros más conocidos. Los ecos de estas reflexiones que, desde nuestro punto de vista, podríamos incluir bajo todo concepto dentro del ámbito de la "filosofía de la historia", estarán presentes en toda su obra posterior, pero será solamente entre agosto de 1974 y marzo de 1975, con ocasión de dos cursos impartidos en el Colegio de México, cuando Xirau volverá a centrar su atención de manera exclusiva en estas cuestiones. Los resultados de todo lo pensado y afirmado durante estos eventos fueron reunidos y publicados por Alianza Editorial en 1975 bajo el título de El desarrollo y la crisis de la filosofía occidental. Xirau hace, evidentemente, referencia a cuanto había expuesto ya en El péndulo y la espiral; es verdad que, con respecto al texto de 1959, acentúa el carácter crítico de la época contemporánea, pero la causa de esta crisis sigue encontrándola en la absolutización de lo relativo:

Lo que Ilamo "crisis" consiste siempre en tomar la parte por el todo y absolutizar la parte como si la parte fuera de hecho el todo. Deificar la parte -llámese placer, llámese intelecto, llámese Progreso o Historia o llámese Hombre cuando el hombre intenta, a veces sin saberlo, a convertirse en su propio dios y acaba por convertirse en su propio ídolo. "Crisis" es así considerar absoluto lo que es tan sólo relativo; crisis es también escindir la persona en partes irreconciliables, llámense éstas amor y razón, o emoción e intelecto. También en este caso "crisis" significa considerar una parte por el todo y así destruir la posible armonía que, dentro de su límite y finitud, los hombres pueden alcanzar y parecen a veces haber

55. Xirau, R., El péndulo, pp. 128; 132. 
alcanzado. Ni emoción pura ni pura emoción, sino recuperación de la emoción reflexiva, de la reflexión emotiva. O, tal vez, recuperación de los grandes signos que son auténticos fundamentos: Logos, Eros. ${ }^{56}$

Los artistas, los creadores, se convierten en la obra de Xirau en las voces de la crisis, término aquí empleado en su sentido etimológico de "cambio". Según el catalán, el estudio de las crisis históricas, mediante sus manifestaciones artísticas, podría arrojar luz sobre los momentos en los que se producen grandes cambios históricos y, también, sobre sus razones. Con más convicción que en el texto de 1959, Xirau demuestra aspirar, como solución para la crisis contemporánea, a un pensamiento "integracionista", a un "pensamiento puente" capaz de abarcar razón y sentimiento y que se decline no exclusivamente en el clásico género del tratado filosófico, sino que se abra a las infinitas posibilidades ofrecidas por las novelas, el ensayo, la poesía y el arte. No cabe duda de que aquí el catalán está pensando en lo que expuso ya en su primer libro filosófico, Sentido de la presencia ${ }^{57}$, a la hora que va situándose conscientemente en la línea de la amplia tradición del pensamiento en lengua española que, como se viene demostrando desde ya los años 80 , ha ido plasmándose en las páginas de libros que han quedado durante mucho tiempo ajenos a los intereses de los historiadores de la filosofía.

Con respecto a El desarrollo y las crisis de la filosofía occidental, tenemos que centrar nuestra atención en otro aspecto fundamental que pone de manifiesto la evolución, a lo largo de los años, de la filosofía de la historia de Xirau. En El péndulo y la espiral, como hemos tenido modo de ver, el pretexto para hablar de la crisis había sido las críticas de algunas filosofías de la historia de los siglos XIX y XX; en cambio, en los cursos de 1974 y 1975, Xirau parece considerar la crisis como un elemento estructural del desarrollo histórico, al punto que la exposición de la historia del pensamiento, desde la Antigua Grecia hasta la Edad Contemporánea, pasando por los pensadores medievales y modernos, se vuelve ahora un pretexto para "proporcionar una pauta que acaso aclare la noción y la vivencia de esto que llamamos 'crisis' de nuestro tiempo" ${ }^{\prime 58}$. Aunque el autor confiese no haber "querido encontrar una 'ley' universal para el desarrollo del pensamiento" ${ }^{\prime 59}$-algo que, como venía diciendo ya desde 1959, no consideraba posible hacer- está claro que entre la escritura de los dos textos ha ido tomando fuerza en el autor la idea de que es posible aclarar el movimiento histórico a través de la aplicación de algún esquema que, sin forzar la misma dinámica histórica, ayude a resaltar algunos momentos fundamentales del pensamiento occidental. En El péndulo y la espiral Xirau señalaba la importancia de lo histo-

56. Xirau, R., El desarrollo y las crisis de la filosofía occidental. Madrid, Alianza, 1975. Aquí utilizamos la edición de 2003 publicada en México por El Colegio Nacional, pp. 2-3.

57. Cfr. Dalla Mora, R., "Invitación al pensamiento", particularmente pp. 16-27.

58. Xirau, R., El desarrollo y las crisis, p. 2.

59. Xirau, R., El desarrollo y las crisis, p. 1. 
riable de la filosofía e intentaba, en un par de breves páginas, resumir y organizar su contenido; en El desarrollo y las crisis de la filosofía occidental este intento se convierte en el tema central de la obra, y la tímida indicación metodológica que Xirau escribía en 1959 se vuelve ahora una convicción filosófica:

Hemos visto que todos los grandes momentos de la filosofía y del pensamiento de Occidente parecen seguir un ritmo que conduce de un primer período de épocas creadoras, aportadoras de novedades, que estas épocas conducen a grandes síntesis, sistemas o summas para proseguir en épocas de decadencia y crisis, donde se toma la parte por el todo y se idoliza y totaliza la parte. ${ }^{60}$

Xirau, obligado a organizar de alguna manera el contenido que expone y de acuerdo con las conclusiones expuestas en El péndulo y la espiral, opta por un esquema del tipo: etapas creadoras-etapas sintéticas-etapas críticas, donde la clave del pasaje de una época a otra reside en la etapa crítica de cada una. Esta metodología le permite responder a las necesidades pedagógicas propias del género manualístico y, por otra parte, disminuir notablemente la resistencia propia de la disciplina histórico-filosófica al fluir dinámico de la historia.

Con respecto a la nueva metodología historiográfica empleada, confiesa haber encontrado en la filosofía de la historia de Vico un método que le permita pasar de una época histórica a la otra sin solución de continuidad, interpretando cada una de ellas como una absorción de la que la precede. Esta metodología le permite poner en diálogo diferentes civilizaciones y períodos históricos sin establecer barreras fijas e infranqueables, lo cual refleja, en opinión de Sánchez Vázquez, la "viva y lúcida conciencia histórica"61 de Xirau. Reproducimos aquí el índice de El desarrollo y las crisis de la filosofía occidental, que sigue siendo la mejor manera para ejemplificar esta metodología:

Parte I. Grecia

1. De ascensos. Heráclito.

2. La síntesis platónica.

3. De crisis. Estoicos, epicuréos, escépticos.

Parte II. Cristianismo y Edad Media

4. De ascenso. Patrística.

5. La síntesis agustiniana.

6. De crisis. Fin de la Edad Media.

60. Xirau, R., El desarrollo y las crisis, p. 167.

61. Sánchez Vázquez, A., "Homenaje a Ramón Xirau”. González, J. (ed.), Presencia, p. 29. 
Parte III. Modernos y contemporáneos

7. Esbozo del Renacimiento.

8. La síntesis hegeliana.

9. Indicios de la crisis contemporánea: Feuerbach, Marx, Kierkegaard.

10. La crisis del siglo $X X{ }^{62}$

Los elementos que hemos ido describiendo hasta ahora constituyen la que definimos la "filosofía de la historia" de Ramón Xirau, teniendo siempre en cuenta los matices que hay que introducir necesariamente a la hora de referirnos a un autor que niega, por todas las razones que hemos ido mencionado, la posibilidad misma de la existencia de una filosofía de la historia entendida en los términos clásicos del mecanicismo. Ahora bien: inevitablemente, la filosofía de la historia trazada por Xirau que, resumiendo, se caracteriza por una descripción que se basa en la alternancia de épocas creadoras, sintéticas y críticas y por la referencia a todo tipo de actividad humana, sin limitarse a las posibilidades ofrecidas por el canon histórico-filosófico tradicional, tendrá una influencia fundamental en su labor como historiador de la filosofía.

Como hemos dicho en un principio, la Introducción a la historia de la filosofía sigue siendo, hoy en día, el libro más conocido y leído de Xirau. Más allá de la obvia difusión que la obra ha tenido, y tiene, al ser empleado como manual de texto en la mayoría de las universidades de México, creemos que el éxito de la Introducción reside, también, en sus características, tanto estructurales como de contenido, que se relacionan indudablemente con las tesis propuestas en los textos que hemos analizado.

Cuando en El péndulo y la espiral Xirau escribía que las filosofías de la historia de Marx, Comte y Spengler eran los productos de la disolución del sistema hegeliano, estaba señalando que estas corrientes sólo son comprensibles si tenemos en cuenta sus antecedentes. Hacía lo mismo, de forma estructurada, en El desarrollo y la crisis de la filosofía occidental, donde pasaba a analizar la historia del pensamiento occidental en su globalidad. Consciente de que todo lo historiable necesita estar encuadrado dentro de esquemas y definiciones, la preocupación constante de Xirau es la de subrayar el carácter funcional de esta metodología, considerándola una herramienta para hacer inteligible el curso histórico que, en realidad, no presenta rupturas sino pura continuidad. El esquema épocas creadoras - épocas sintéticas - épocas críticas responde a esta necesidad pedagógica y, sin embargo, no pone barreras al dinámico fluir histórico. El intento de la obra historiográfica de Xirau es "señalar algunos 'extremos' del pensamiento occidental"63 sin querer definir por ello de un modo definitivo una determinada

62. Xirau, R., El desarrollo y las crisis, p. VII.

63. Xirau, R., El desarrollo y las crisis, p. 2. 
época histórica. Por todo esto, Xirau no escribe una historia de la filosofía, sino una Introducción: nos encontramos, entonces, con autores clásicos como Sócrates, Platón, Aristóteles, Agustín, Tomás de Aquino, Descartes, Espinoza, Leibniz, Hobbes, Rousseau, Kant, Hegel, Schopenhauer, Marx, Nietzsche, Bergson, Husserl. Pero, por otra parte, hay nombres por entonces menos comunes dentro del canon clásico de la historiografía filosófica, como: Ortega y Gasset, Unamuno, Machado, Pierre Teilhard de Chardin, nombres que responden a la necesidad de explicar el curso histórico desde un punto de vista particularísimo -que es la perspectiva del autor y de la tradición de pensamiento a la que pertenece-, en tanto que es imposible y artificial, por todo lo dicho, realizar esta tarea presumiendo un punto de vista absoluto y totalmente objetivo.

Queda bastante claro por qué la obra histórica de Ramón Xirau ha sido capaz de "iniciar a tantos alumnos en su navegar por las vías fluviales del pensamiento filosófico" ${ }^{\prime 64}$. En su crítica a las teorías históricas más importantes de los siglos XIX y XX, Xirau se ha hecho consciente de las limitaciones propias de todas las explicaciones mecanicisticas del curso histórico y ha reflexionado sobre la posibilidad de una filosofía de la historia capaz de acercarse al desarrollo del espíritu humano. En su búsqueda ha comprendido las problemáticas que presenta un enfoque que se escapa a la interdisciplinariedad y ha creído encontrar en el concepto de crisis la clave para poner en relación épocas históricas diferentes. Situándose en la contradicción y asumiéndola en lugar de escapar de ella -es decir, poniendo de manifiesto el carácter contradictorio y dogmático propio del período crítico, en lugar de buscar una solución racional y totalizadora-, Xirau ha convertido en filósofos a autores no canónicos de la historiografía filosófica, como novelistas, poetas y artistas. Estos elementos han ido a conformar así un edificio intelectual singular, capaz de oír las múltiples voces de las diferentes culturas y civilizaciones e invitar, sin un ánimo dogmático, a iniciarse en el estudio del curso histórico de la disciplina filosófica. En otras palabras, Introducción a la historia de la filosofía permite a cualquiera sentirse en su propia casa, y no obliga a tomar partido, apriorísticamente, por ningún punto de vista, sino que invita a explorar la propia dinámica de la historia, haciendo patente constantemente la imposibilidad de reducirla a un esquema mecánico.

Podría parecer que todo esto es solamente el resultado de un enorme esfuerzo teorético realizado por Xirau en sus reflexiones anteriores a la publicación de la Introducción. Por un lado es cierto que existe, y esta investigación pretende precisamente sacar a relucir esta relación; sin embargo, parece que en Xirau esta particular comprensión de la dinámica histórica es fruto más bien de una original sensibilidad que, a su vez, se relaciona íntimamente con su propia experiencia personal. La Introducción a la historia de la filosofía podía haber sido escrita solamente por alguien que hubiera vivido con las entrañas, y no tan sólo con la

64. Hierro, G., "Ramón Xirau y la historia de la filosofía". González, J. (ed.), Presencia, p. 98. 
razón, el exilio, el transtierro -según el término gaosiano-, la integración entre corrientes y naturalezas tan aparentemente contradictorias como la filosofía del sentido común escocés -traducida en el estilo característico de la tradición de pensamiento catalán-, de la mística española, de la vanguardia europea de los años 30, del pensamiento indígena precolombino, de la analítica y el pragmatismo estadounidense y un largo etcétera. Por todo eso, concordamos plenamente con Graciela Hierro cuando destaca la unicidad de la especulación históricofilosófica -o filosófico-historiográfica- de Ramón Xirau en estos términos:

Puede pensarse que el historiador de la filosofía es como el nieto que cuestiona al abuelo [...] En este sentido, Ramón es un nieto muy especial. En primer lugar es un nieto mexicano-catalán que habla, en su historia, del lago de Pátzcuaro, de fray Bartolomé de las Casas, de Vives y Unamuno. En esa medida, Ramón plantea preguntas particulares y diferentes de las de otros historiadores. ${ }^{65}$

65. Hierro, G., "Ramón Xirau”, pp. 95-96. 